\title{
Above-water reflectance for the evaluation of adjacency effects in Earth observation data: initial results and methods comparison for near-coastal waters in the Western Channel, UK
}

V. Martinez-Vicente vmv@pml.ac.uk

S. G. H. Simis

R. Alegre

P. E. Land

S. B. Groom
Plymouth Marine Laboratory, Prospect Place, The Hoe, PL1 3DH, Plymouth, UK

Finnish Environment Institute SYKE, Erik Palménin Aukio 1, 00251, Helsinki, Finland

Plymouth Marine Laboratory, Prospect Place, The Hoe, PL1 3DH, Plymouth, UK

Plymouth Marine Laboratory, Prospect Place, The Hoe, PL1 3DH, Plymouth, UK

Un-supervised hyperspectral remote-sensing reflectance data ( $<15 \mathrm{~km}$ from the shore) were collected from a moving research vessel. Two different processing methods were compared. The results were similar to concurrent Aqua-MODIS and Suomi-NPP-VIIRS satellite data. [DOI: http://dx.doi.org/10.2971/jeos.2013.13060]

Keywords: Adjacency effect, above-water reflectance, coastal waters, Earth observation

\section{INTRODUCTION}

The use of near-coastal (less than $15 \mathrm{~km}$ from the shore) satellite ocean colour data is limited by difficulties with: adjacency effects [1], atmospheric correction [2] and in-water optical complexity [3]. A large effort in the scientific community has been dedicated to the development of atmospheric correction models [4]-[7] and algorithms for separating the signal from optically active components in coastal waters [8]-[11]. Comparatively, less effort has been dedicated to the investigation of the adjacency effect [12], which is critical in near-coastal imagery. Conceptually, the adjacency effect is due to the presence of a scattering atmosphere over a reflecting surface that is nonuniform. This causes the radiance from high reflectivity areas to "spill" over the neighbouring low reflectivity areas, increasing their apparent brightness and modifying observed spectral properties. With the increased current and planned use of satellites for water quality assessment and a profound interest in biogeochemical processes and water quality in the nearshore environment, there is a need to refine remotely sensed product quality in the near-coastal area, and therefore to better understand the adjacency effect.

In order to improve our knowledge of coastal adjacency effects, in-situ remote sensing reflectance $\left(R_{r s}\right)$ data would ideally be gathered from transects perpendicular to the coastline. In addition, to be able to test adjacency effect algorithms, the in-situ data would have to be matched with concurrent satellite imagery. Unfortunately, such data collection implies uncertain planning and examples in the literature are scarce. $R_{r s}$ spectra were measured over very turbid waters off the Belgian coast [13]. Alternatively, a modelling approach has been proposed in the absence of in-situ data of those characteristics.
This approach used a 3D backward Monte Carlo code and Finite Elements Method plane-parallel radiative transfer codes to simulate adjacency effects near the coast [14]. Having to resort to a modelled dataset highlights the need for a dataset collected specifically with the purpose of testing adjacency effect correction schemes.

The present work reports on in-situ un-supervised $R_{r s}$ measurements from above water hyperspectral radiometers. Uncertainty in above-water radiometry arises from: instrument calibration and performance, correction for air-sea interface reflection and optical changes of the water related to the measurement platform (like ship perturbation of the light field) $[15,16]$. In this work we specifically quantify the discrepancies arising from the air-sea interface reflection correction parts and the influences on derived $\mathrm{R}_{\mathrm{rs}}$. We do so by processing the same data with two methods: the similarity spectra [17] and the fingerprint approach [18]. Preliminary results on the comparison of in-situ $\mathrm{R}_{\mathrm{rs}}$ data with ocean colour images using standard processing algorithms are also presented. The concurrent in-situ and satellite observations will be useful to the scientific community developing corrections of the adjacency effect in current and upcoming sensors.

\section{METHODS}

We designed a sampling strategy to collect suitable datasets for testing algorithms in coastal waters off Plymouth (UK). These are land influenced and yellow substance dominated waters, while relatively clear of particles (chlorophyll con- 


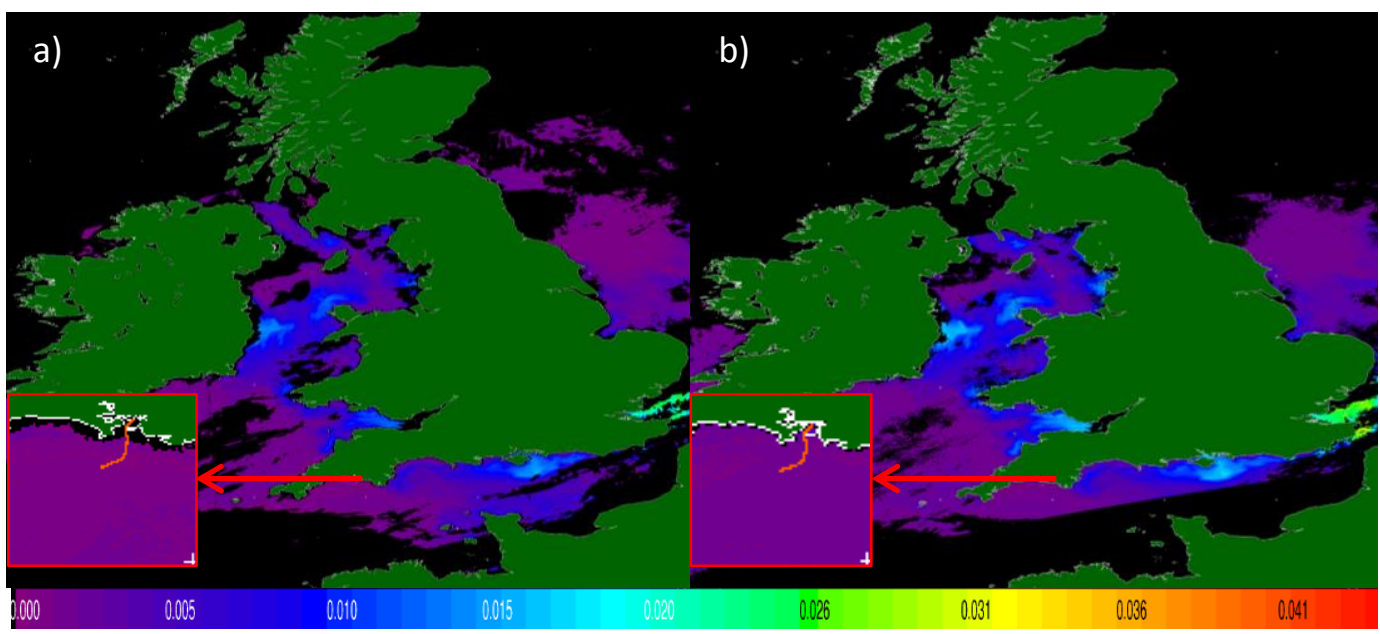

FIG. 1 Satellite images from 5-Sep-2012: a) MODIS-A R $\mathrm{rS}_{\mathrm{S}}\left(555 \mathrm{~nm}\right.$ ) at 12:26 (500 m resolution), b) VIIRS R $\mathrm{rS}_{\mathrm{rS}}(551)$ at 12:45 (740 m). Insets of the Plymouth coastal area highlight the sampling transect.

centration (Chl-a) around $1.5 \mathrm{mg} \cdot \mathrm{m}^{-3}$, suspended particulate matter (SPM) $\left.1 \mathrm{~g} \cdot \mathrm{m}^{-3}\right)[19,20]$. Weekly monitoring of a long term time series station (L4) and the wider scientific activities within the Western Channel Observatory (http://www. westernchannelobservatory.org.uk/) offer multiple possibilities for opportunistic sampling of a transect perpendicular to the coast.

In-situ sampling took place on the RV Plymouth Quest $\left(5^{\text {th }}\right.$ $7^{\text {th }}$ Sept. 2012), during a quasi-perpendicular transect to the coast off Plymouth, while the vessel carried out other routine tasks. Only data from the $5^{\text {th }}$ September between 09:22 a.m. and 11:30 a.m. GMT were co-incident with clear satellite imagery (Figure 1). Un-supervised sampling of above water radiometric quantities was performed using a hyperspectral HyperSAS system (Satlantic Inc. Halifax, Canada), composed of three sensors simultaneously measuring downwelling irradiance $\left(E_{d}\right)$, sky radiance $\left(L_{s}\right)$ and water leaving radiance $\left(L_{t}\right)$. This system also included a Satlantic tilt, heading and roll sensor (THR) and GPS. The three optical sensors were mounted on a pole on the bow of the vessel at $5 \mathrm{~m}$ above the water surface. $L_{t}$ was measured pointing to the water surface with an angle of $\sim 40^{\circ}$ from nadir (i.e. viewing zenith angle, $\theta_{\mathrm{v}}$ ) and the crew was instructed to measure away from the sun (viewing azimuth angle, $\phi_{\mathrm{v}}$ ) with an angle $\sim 135^{\circ}$ [21], whenever possible during other routine operations. The sensors collected data semi-continuously with $3.3 \mathrm{~nm}$ spectral resolution between 350 and $800 \mathrm{~nm}$, with a scanning frequency between 4 and $0.5 \mathrm{~Hz}$, depending on the sensor optics. The optical data were converted to physical units and processed to Level3a using the manufacturers software (Prosoft v7.7.16) which merged the data to $1 \mathrm{~Hz}$. The calibration of the optical instruments had been done by the manufacturer previous to the deployment (April 2012). The optical sensors have a nominal calibration uncertainty of 3\% (Satlantic Inc., personal communication).

We used wind speed and an index of the cloud coverage changes (i.e. $\left.\pi \mathrm{L}_{\mathrm{s}}(400) / \mathrm{E}_{\mathrm{d}}(400)\right)$ to characterise measurement conditions.

\subsection{Data processing}

We used two different approaches to compute the air-sea interface reflection $\left(\rho_{\text {sky }}\right)$ and to correct for sun-glint contamination. The first approach (i.e. similarity spectra) [17] expresses $\rho_{\text {sky }}$ as a function of wind speed, derived from Hydrolight computations [21]. This includes a switch to an overcast sky model when $\mathrm{L}_{\mathrm{s}}(750) / \mathrm{E}_{\mathrm{d}}(750)>0.05$, when $\rho_{\text {sky }}$ is assigned a constant value of 0.0256 . This approach is also used to calculate the remote sensing reflectance $\left(R_{r s}\right)$, based on the observation that $R_{r s}$ in the NIR has a constant shape in moderately turbid to turbid waters. The method was originally developed using model RAMSES sensors from TriOS Optical Systems (Rastede, Germany). We applied the method to the Satlantic HyperSAS instrument. A major difference between the two instruments was their spectral range: 320 to $950 \mathrm{~nm}$ for the TriOS and 350 to 800 for HyperSAS. This difference caused our choice of reference wavelengths for the similarity spectra to be $\lambda_{1}=720 \mathrm{~nm}$ and $\lambda_{2}=780 \mathrm{~nm}$, as opposed to 779 and $865 \mathrm{~nm}$ from the original publication [17].

The second approach used in this work was developed for unsupervised sampling on ferries in the Baltic Sea [18] (i.e. fingerprint approach). This spectral optimization method retrieves $\rho_{\text {sky }}$ by minimizing the propagation of atmospheric absorption features to $R_{r s}$. The model provided flags for values of $\rho_{\text {sky }}$ too low (lower than 0.0240 ), too high (when $\rho_{\text {sky }}$ yields $\mathrm{R}_{\mathrm{rs}}=0$ in any waveband between 375 and $800 \mathrm{~nm}$ ) or suspect (when $\rho_{\text {sky }}$ yields negative $R_{r s}$ in the same spectral range).

\subsection{Statistics}

We follow the convention of Hooker et al. [22] and use an unbiased parameter, because we do not assume either of the processing methods to be more correct than the other. Comparison between the two processing methods was quantified using the unbiased percent difference (UPD) computed as:

$$
\mathrm{UPD}=200 \times\left(\frac{\left|X_{i}^{F}-X_{i}^{S}\right|}{X_{i}^{F}+X_{i}^{S}}\right)
$$



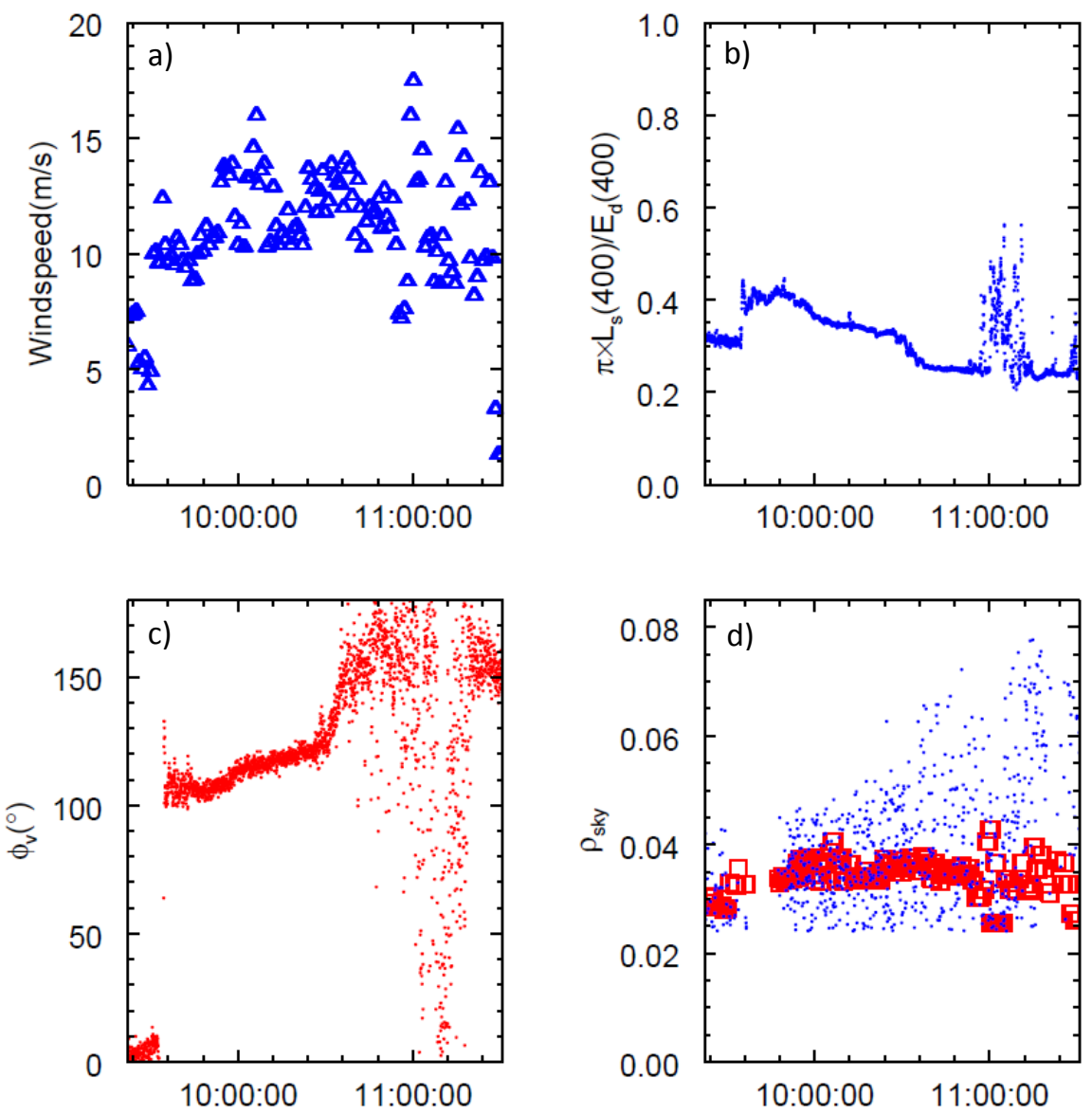

FIG. 2 Sampling conditions during the transect ( $5^{\text {th }}$ September 2012). a) Wind speed, b) Cloudiness index, $c$ ) Viewing azimuth angle, $\left.\phi_{V}, d\right)$ Matching $\rho_{\text {sky }}$ calculated using the wind speed - similarity spectra (red squares) and the fingerprint approach (blue dots).

where $X$ is the variable being compared for a given spectra, $i$, the superscript $F$ is for the fingerprint approach and $S$ is for the similarity spectra.

Stable meteorological conditions prevailed during the week when sampling was performed. On the sampling day, relatively high median wind speed of $11 \pm 2 \mathrm{~m} / \mathrm{s}$ was recorded together with clear sky and stable cloud cover conditions (Figure 2). It can be seen how the most stable $\phi_{\mathrm{v}}$ were obtained between 9:35 and 10:30 (Figure 2(c)).

\subsection{Remote sensing data}

The remote sensing data used in this study have been obtained from two different sensors: the Moderate Resolution Imaging Spectroradiometer (MODIS) carried on board of NASA's satellite Aqua, and the Visible Infrared Imaging Radiometer Suite (VIIRS), on board of NOAA's Suomi NPP satellite. MODIS L1A data were downloaded from the Ocean Color Web Page (http://oceancolor.gsfc.nasa.gov). These data were processed by SeaDAS (http://seadas.gsfc.nasa.gov/) to generate the $\mathrm{L} 2$ geolocated $\mathrm{R}_{\mathrm{rs}}$ data, masking out the land and clouds. We used MODIS images at $500 \mathrm{~m}$ spatial resolution. VIIRS L2 data were also downloaded from the Ocean Color Web Page. These data were generated by NASA experimental processing. VIIRS images have a resolution of $740 \mathrm{~m}$. Data corresponding to the transect from offshore to the coastline was were extracted from the Remote Sensing images using the BEAM Toolbox (http://www.brockmann-consult.de/cms/web/beam/) to compare with the in-situ measurements (Figure 1).

\section{RESULTS AND DISCUSSION}

All $\rho_{\text {sky }}$ values obtained from the similarity spectra and the fingerprint approach are shown in Figure 2(c). When the similarity spectra data filtering criteria were used to filter the spectra [23] for the whole sampling period (i.e. 9:22 to 11:30), the number of valid data was reduced from 2607 to 279 (10.7\%). On the other hand, when the fingerprint approach was used, the percentage of valid $\rho_{\text {sky }}$ was $28.8 \%$. The remaining $\rho_{\text {sky }}$ values were flagged as too low (29.4\%), too high $(41.3 \%)$ and suspect $(0.5 \%)$. The intersection between the acceptable spectra for the similarity spectra and valid data from the fingerprint approach yielded 84 spectra $(3.2 \%)$, which were used for the comparison hereafter. Median $\pm 68^{\text {th }}$ percentiles of $\rho_{\text {sky }}$ for the similarity spectra and fingerprint approach were respectively: $0.0345 \pm 0.003$ and $0.0384 \pm 0.015$. The average UPD was $26 \%$ and no significant correlation between UPD and $\phi_{\mathrm{v}}$ was found. However, selecting only data from the period with stable $\phi_{\mathrm{v}}$ (i.e. 9:35 to 10:30, $\mathrm{N}=33$, or $1.3 \%$ of 2607 ), reduced the average UPD to $20 \%$. 
The discrepancy in $\rho_{\text {sky }}$ translated into spectral $R_{\text {rs }}$. Average UPD was higher for the blue bands than for green: $45.3 \%$ at $412 \mathrm{~nm}$ and $18.5 \%$ at $555 \mathrm{~nm}$. The mean spectral UPD for the most common bands in that interval (i.e. 412, 442, 488 and 555 ) was $27.9 \%$. A similar comparison between other methods for processing above water radiometry [22] produced much lower mean UPD values for clear sky days (e.g. average spectral UPD was $1.2 \%$ ). The fingerprint approach would benefit from inclusion of spectral radiance in the 320-400 $\mathrm{nm}$ domain since there are some major gas absorption features there. This may also explain to some extent why blue bands show larger discrepancies. Further testing of this hypothesis is needed by extending the HyperSAS spectral range to wavelengths below the current $350 \mathrm{~nm}$ limit.

Overall agreement between in-situ (not-normalised) $R_{r s}$ and satellite $R_{r s}$ can be observed (Figure 3), with VIIRS data being closer to in-situ observations than MODIS for the whole transect. There is an increase in $R_{r s}$ near to the coast in the in-situ data and VIIRS, but not valid data in the MODIS $500 \mathrm{~m}$ image. This highlights the potential for the use of coupled satellitesnear shore in-situ data to improve the correction of the adjacency effect in coastal waters.

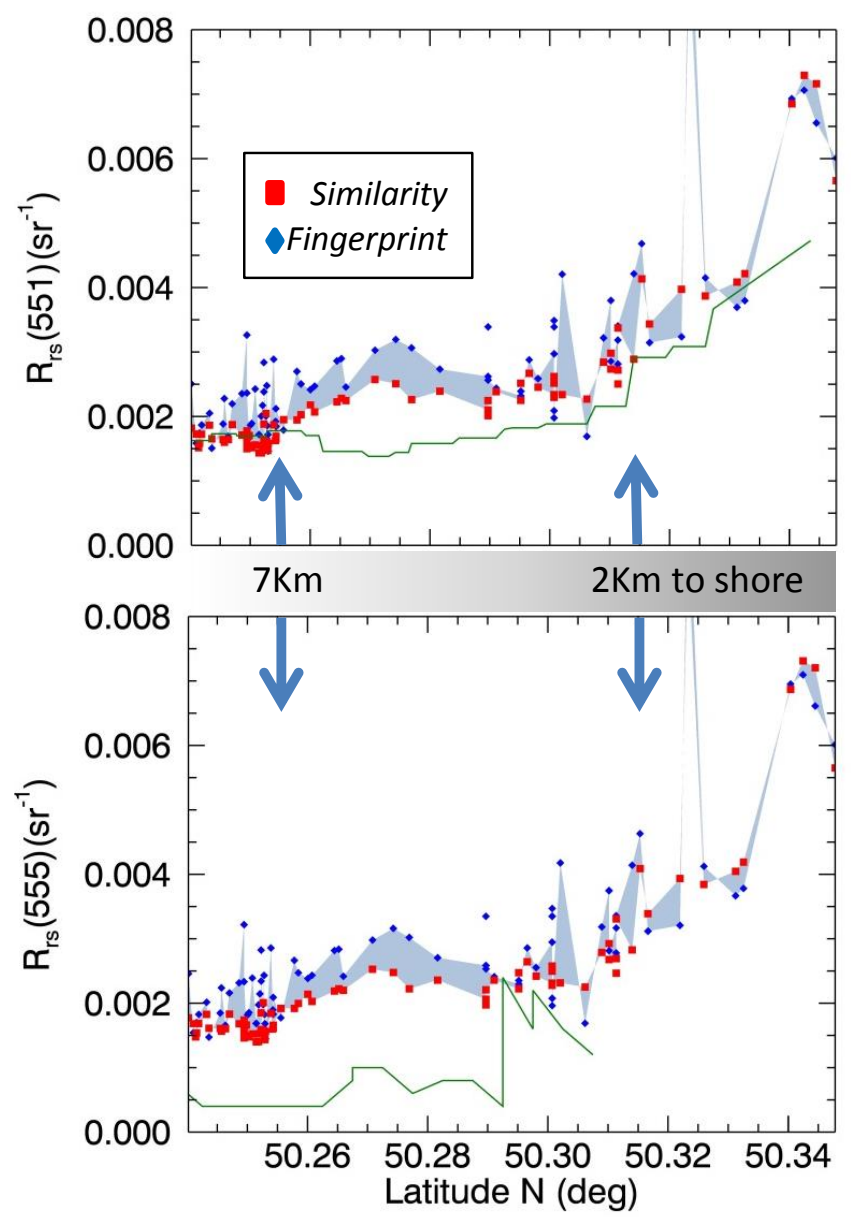

FIG. 3 Comparison of in-situ Hypersas with satellite data. In-situ data at $555 \mathrm{~nm}$ were processed with similarity and fingerprint methods. Blue area highlights the difference between the two processing methods, as a measure of the uncertainty on the in-situ data. Green solid line are satellite data: a) VIIRS 551 band (750 $\mathrm{m}$ spatial resolution). b) MODIS-A 555 band ( $500 \mathrm{~m}$ and $1 \mathrm{~km}$ resolution). Arrows mark the approximate distance to the shore in the grey scale area (darker grey is nearer to shore, i.e. $\sim 50.35^{\circ} \mathrm{N}$ )

\section{CONCLUSIONS AND OUTLOOK}

We have presented initial results from a sampling designed to collect in-situ above water reflectance data to initiate the creation of a dataset suitable to evaluate adjacency effect models in coastal waters. In order to gain confidence in this dataset, we have explored two sources of uncertainty: viewing azimuth sampling and data processing.

This study has concluded that maintaining constant viewing angles reduced the differences between two processing methods to $20 \%$. Correct and constant viewing angles also provided, qualitatively, better agreement with concurrent MODIS and VIIIRS (experimental) full resolution satellite data. In the case of un-supervised sampling, this argument supports the use of automatic azimuth adjusting platforms such as the RFlex system [24]. Concerning the data processing, two recent methods have been used in this study giving a large discrepancy. Sources of this discrepancy could be the differences in spectral range between the instruments used in our study and those originally used in the development of the fingerprint approach. This hypothesis needs to be tested in the future. Because the Plymouth coastal area has a low sediment load, the present comparison of methods could also be extended to include additional methods for the air-sea interface correction in use for clear waters [25] and other recent processing methods for coastal waters [26].

The viewing geometry of above water sensors and the processing methods used are just two of the sources of uncertainty in the correction for air-sea interface reflection. Other sources of error need to be further investigated (i.e. wave slope statistics, integration time, sky radiance distribution, instrument deployment from a moving platform) [15, 16]. A more complete uncertainty analysis is therefore required as well as cross comparisons with similar measurements in the area by other teams [17].

Through a better characterisation of the uncertainties, we expect to provide robust and useful datasets for the study of the adjacency effect on Earth observation images of coastal areas.

\section{ACKNOWLEDGEMENTS}

This work is based on a presentation at the EOS topical meeting "Blue photonics 3 - Optics of the Sea" held in Texel (NL), in March 2013. This research has been funded through the project ISECA, part of the Interreg IV A 2Seas program. The authors thank the captain and the crew of the RV Plymouth Quest for their help with the data collection and J. Fishwick for the underway wind data. We acknowledge the comments from an anonymous reviewer that helped improving this paper.

\section{References}

[1] R. Santer, and C. Schmechtig, "Adjacency effects on water surfaces: primary scattering approximation and sensitivity study," Appl. Optics 39, 361-375 (2000). 
[2] M. Wang, Atmospheric Correction for Remotely-Sensed OceanColour Products (IOCCG Report 10, 2010).

[3] S. Sathyendranath, Remote sensing of ocean colour in coastal, and other optically-complex waters (IOCCG Report 3, 2000).

[4] S. J. Lavender, M. H. Pinkerton, G. F. Moore, J. Aiken, and D. Blondeau-Patissier, "Modification to the atmospheric correction of SeaWiFs ocean colour images over turbid waters," Cont. Shelf Res. 25, 539-555 (2005).

[5] G. F. Moore, J. Aiken, and S. J. Lavender, "The atmospheric correction of water colour and the quantitative retrieval of suspended particulate matter in Case II waters: application to MERIS," Int. J. Remote Sens. 20, 1713-1733 (1999).

[6] C. M. Hu, K. L. Carder, and F. E. Muller-Karger, "Atmospheric correction of SeaWiFs imagery over turbid coastal waters: A practical method," Remote Sens. Environ. 74, 195-206 (2000).

[7] K. G. Ruddick, F. Ovidio, and M. Rijkeboer, "Atmospheric correction of SeaWiFs imagery for turbid coastal and inland waters," Appl. Optics 39, 897-912 (2000).

[8] Z. P. Lee, K. L. Carder, and R. A. Arnone, “Deriving inherent optical properties from water color: a multiband quasi-analytical algorithm for optically deep waters," Appl. Optics 41, 5755-5772 (2002).

[9] S. Maritorena, D. A. Siegel, and A. R. Peterson, "Optimization of a semianalytical ocean color model for global-scale applications," Appl. Optics 41, 2705-2714 (2002).

[10] J. E. O'Reilly, S. Maritorena, B. G. Mitchell, D. A. Siegel, K. L. Carder, S. A. Garver, M. Kahru, and C. McClain, "Ocean color chlorophyll algorithms for SeaWiFS," J. Geophys. Res.-Oceans 103, 24937-24953 (1998).

[11] T. J. Smyth, G. F. Moore, T. Hirata, and J. Aiken, "Semianalytical model for the derivation of ocean color inherent optical properties: description, implementation, and performance assessment," Appl. Optics 45, 8116-8131 (2006).

[12] S. Bélanger, J. K. Ehn, and M. Babin, "Impact of sea ice on the retrieval of water-leaving reflectance, chlorophyll a concentration and inherent optical properties from satellite ocean color data," Remote Sens. Environ. 111, 51-68 (2007).

[13] S. Sterckx, E. Knaeps, and K. Ruddick, "Detection and correction of adjacency effects in hyperspectral airborne data of coastal and inland waters: the use of the near infrared similarity spectrum," Int. J. Remote Sens. 32, 6479-6505 (2011).

[14] B. Bulgarelli, V. Kisselev, and G. Zibordi. Oceans from space. 2010. Venice, Italy: Joint Research Centre, EC.
[15] G. Zibordi, S. B. Hooker, J. F. Berthon, D. D'Alimonte, "Autonomous above-water radiance measurements from an offshore platform: a field assessment experiment," J. Atmos. Ocean. Tech. 19, 808-819 (2002).

[16] K. Ruddick, V. de Cauwer, and Y.-J. Park, "Web Appendix 2: Measurement uncertainty analysis," Limnol. Oceanogr. 51, 1167-1179 (2006).

[17] K. Ruddick, V. de Cauwer, and Y.-J. Park, "Seaborne measurements of near infrared water-leaving reflectance: The similarity spectrum for turbid waters," Limnol. Oceanogr. 51, 1167-1179 (2006).

[18] S. G. H. Simis and J. Olsson, "Unattended processing of shipborne hyperspectral reflectance measurements," Remote Sens. Environ. 135, 202-212 (2013).

[19] V. Martinez-Vicente, P. E. Land, G. H. Tilstone, C. Widdicombe, and J. R. Fishwick, "Particulate scattering and backscattering related to water constituents and seasonal changes in the Western English Channel," J. Plankton Res. 32, 603-619 (2010).

[20] S. B. Groom, V. Martinez-Vicente, J. R. Fishwick, G. Tilstone, G. Moore, T. J. Smyth, and D. Harbour, "The western English Channel observatory: Optical characteristics of station L4," J. Marine Syst. 15, 20-50 (2009).

[21] C. D. Mobley, "Estimation of the remote-sensing reflectance from above-surface measurements," Appl. Optics 38, 7442-7455 (1999).

[22] S. B. Hooker, G. Lazin, G. Zibordi, and S. McLean, "An evaluation of above- and in-water methods for determining water-leaving radiances," J. Atmos. Ocean. Tech. 19, 486-515 (2002).

[23] K. Ruddick, V. de Cauwer, and Y.-J. Park, "Web Appendix 1. Data processing: scan selection and averaging," Limnol. Oceanogr. 51, 1167-1179 (2006).

[24] J. Olsson and S. G. H. Simis. RFlex: Spectroradiometer control for shipborne reflectance measurements. 2012; Available from: http: //sourceforge.net/projects/rflex/.

[25] S. P. Garaba and 0. Zielinski, "Comparison of remote sensing reflectance from above-water and in-water measurements west of Greenland, Labrador Sea, Denmark Strait, and west of Iceland," Opt. Express 21, 15938-15950 (2013).

[26] T. Kutser, E. Vahtmäe, B. Paavel, and T. Kauer, "Removing glint effects from field radiometry data measured in optically complex coastal and inland waters," Remote Sens. Environ. 133, 85-89 (2013). 